\title{
IL10 low-frequency variants in Behçet's disease patients
}

\author{
Mafalda MATOS, ${ }^{1,2}$ Joana M. XAVIER, ${ }^{1,2}$ Patrícia ABRANTES, ${ }^{1,2}$ Inês SOUSA, ${ }^{1,2}$ Nádia \\ REI, ${ }^{1,2}$ Fereydoun DAVATCHI, ${ }^{3}$ Farhad SHAHRAM, ${ }^{3}$ Gorete JESUS, ${ }^{4}$ Filipe BARCELOS, ${ }^{5}$ \\ Joana VEDES, ${ }^{6}$ Manuel SALGADO, ${ }^{7}$ Bahar Sadeghi ABDOLLAHI, ${ }^{3}$ Abdolhadi NADJI, ${ }^{3}$ \\ Maria Francisca MORAES-FONTES, ${ }^{2,8}$ Niloofar Mojarad SHAFIEE, ${ }^{3}$ Fahmida \\ GHADERIBARMI, ${ }^{3}$ José VAZ PATTO $^{5}{ }^{\text {Jorge }}$ CRESPO $^{9}$ and Sofia A. OLIVEIRA ${ }^{1,2}$ \\ ${ }^{1}$ Instituto de Medicina Molecular, Faculdade de Medicina da Universidade de Lisboa, Lisboa, ${ }^{2}$ Instituto Gulbenkian de Ciência, \\ Oeiras, Portugal, ${ }^{3}$ Rheumatology Research Center, Tehran University of Medical Sciences, Tehran, Iran, ${ }^{4}$ Hospital Infante D. Pedro, \\ Aveiro, ${ }^{5}$ Instituto Português de Reumatologia, Lisboa, ${ }^{6}$ Hospital de Sousa Martins, Guarda, ${ }^{7}$ Hospital Pediátrico de Coimbra, \\ Coimbra, ${ }^{8}$ Hospital Curry Cabral, Lisboa, and ${ }^{9}$ Hospitais da Universidade de Coimbra, Coimbra, Portugal
}

\begin{abstract}
Aim: To explain the missing heritability after the genome-wide association studies era, sequencing studies allow the identification of low-frequency variants with a stronger effect on disease risk. Common variants in the interleukin 10 gene (IL10) have been consistently associated with Behçet's disease (BD) and the goal of this study is to investigate the role of low-frequency IL10 variants in BD susceptibility.

Methods: To identify IL10 low-frequency variants, a discovery group of 50 Portuguese BD patients were Sangersequenced in a $7.7 \mathrm{~kb}$ genomic region encompassing the complete IL10 gene, $0.9 \mathrm{~kb}$ upstream and $2 \mathrm{~kb}$ downstream, and two conserved regions in the putative promoter. To assess if the novel variants are BD- and/or Portuguese-specific, they were assayed in an additional group of BD patients (26 Portuguese and 964 Iranian) and controls (104 Portuguese and 823 Iranian).

Results: Rare IL10 coding variants were not detected in BD patients, but we identified 28 known single nucleotide polymorphisms with minor allele frequencies ranging from 0.010 to 0.390 , and five novel non-coding variants in five heterozygous cases. ss836185595, located in the IL10 $3^{\prime}$ untranslated region, was also detected in one Iranian control individual and therefore is not specific to BD. The remaining novel IL10 variants (ss836185596 and ss836185602 in intron 3, ss836185598 and ss836185604 in the putative promoter region) were not found in the replication dataset.

Conclusion: This study highlights the importance of screening the whole gene and regulatory regions when searching for novel variants associated with complex diseases, and the need to develop bioinformatics tools to predict the functional impact of non-coding variants and statistical tests which incorporate these predictions.
\end{abstract}

Key words: Behçet's disease, IL10, low-frequency variants, sequencing, susceptibility.

Correspondence: Dr Sofia A. Oliveira, Instituto de Medicina Molecular, Faculdade de Medicina da Universidade de Lisboa, Av. Prof. Egas Moniz, Edifício Egas Moniz, 1649-028 Lisboa, Portugal.

Email: aaoliveira@fm.ul.pt

\section{INTRODUCTION}

Behçet's disease (BD) is an immune-mediated inflammatory vasculitis with a large clinical spectrum, including oral aphthae, genital ulcerations, uveitis, as well as vascular, neurological, articular, pulmonary and gastrointestinal manifestations. ${ }^{1}$ In complex diseases such as 
$\mathrm{BD}$, genome-wide association studies (GWAS) have provided new insights into disease physiopathology through the identification of common genetic variants (minor allele frequencies [MAF] greater than 5\%) associated with disease susceptibility. ${ }^{2,3}$ However, these single nucleotide polymorphisms (SNPs) typically confer a small disease risk and only explain a modest portion of the overall genetic variance. ${ }^{4}$ In addition, many SNPs captured by GWAS seem to be in linkage disequilibrium with the causal variant rather than to be causal themselves, and most of the associated genetic variants do not have any known or obvious functions. ${ }^{5,6}$ Moreover, low-frequency $(1 \% \leq \mathrm{MAF}<5 \%)$ and rare variants $(\mathrm{MAF}<1 \%)$ are not sufficiently frequent to be captured by GWAS and current efforts to discover these variants by sequencing have focused on genes within regions implicated by GWAS. ${ }^{7}$

In addition to the well-established human leukoctye antigen (HLA) locus, common polymorphisms in interleukin (IL23R-IL12RB2) and IL10 have been recently associated with BD in two independent GWAS in Turkish and Japanese datasets ${ }^{2,3}$ and replicated in an Iranian sample ${ }^{8}$ and in a recent meta-analysis. ${ }^{9}$ IL10 has a central role in the suppression of inflammatory cytokines inhibiting the costimulatory activity of macrophages for T-cell and natural killer (NK)-cell activation. IL10 deficiencies add to the group of primary immunodeficiencies and result in severe deregulation of the immune system. ${ }^{10}$ Interestingly, elevated IL10 levels have been observed in the sera and mucocutaneous lesions of $\mathrm{BD}$ patients. ${ }^{11}$ It is likely that relative levels of cytokine production may be important in the determination of disease onset, progression and outcome, and therefore we hereby chose to focus our attention on IL10.

To further investigate the role of low-frequency IL10 variants in $\mathrm{BD}$ susceptibility, we sequenced the complete IL10 gene and neighboring genomic regions, including two well-conserved regions in the putative promoter. The existence and association with $\mathrm{BD}$ of identified novel variants was then assessed in a second independent dataset.

\section{PATIENTS AND METHODS}

\section{Study subjects}

The 76 Portuguese BD patients were recruited throughout Portugal and 104 Portuguese controls were selected among blood bank donors or healthy volunteers using the same evaluation procedures used for the cases; individuals were included as controls when negative for $\mathrm{BD}$, any other rheumatologic or autoimmune disorder, oral and genital aphthosis. The Iranian dataset included 1787 unrelated subjects (964 BD cases and 823 controls) recruited at the Rheumatology Research Center of Shariati Hospital (Tehran University of Medical Sciences, Tehran, Iran). The diagnosis of $\mathrm{BD}$ was made according to the revised International Criteria for Behçet's Disease. ${ }^{1}$ Patients with age at onset of BD after 60 years were excluded. The clinical and demographic features of the participants were obtained by medical interview at the time of blood sampling and inspection of medical records. All participants were informed of the study, provided informed written consent and the study was conducted according to the Declaration of Helsinki. This study received ethics approval from the ethics committees in Portugal (Hospital Infante D. Pedro and Instituto Português de Reumatologia) and Iran (Tehran University for Medical Sciences).

\section{Sample preparation}

Blood samples were drawn into ethylenediaminetetraacetic acid (EDTA) tubes and stored at $-20^{\circ} \mathrm{C}$ until genomic DNA was extracted using QIAamp ${ }^{\circledR}$ DNA Blood Maxi kits (Qiagen, Germantown, MD, USA) or a salting out procedure and diluted in Tris-EDTA (TE) buffer. The concentrations of extracted DNA were determined by Nanodrop using absorbance readings at $260 \mathrm{~nm}$ and the DNAs were then stored at $4{ }^{\circ} \mathrm{C}$.

\section{Sequencing}

To sequence the IL10 open reading frame and two conserved promoter regions, 13 primer sets (Table S1) were designed using the PRIMER3 software (http://bioinfo. ut.ee/primer3/). Polymerase chain reaction (PCR) amplification was carried out in $12.5 \mu \mathrm{L}$ reaction mixtures containing: $25 \mathrm{ng}$ of genomic DNA, $0.004 \mu \mathrm{g} / \mu \mathrm{L}$ of each primer, $1 \times$ PCR reaction buffer, $0.2 \mathrm{mmol} / \mathrm{L}$ deoxynucleotide triphosphate (dNTP), $1.5 \mathrm{mmol} / \mathrm{L}$ $\mathrm{MgCl}_{2}$, and $0.05 \mathrm{U} / \mu \mathrm{L}$ Vent $_{\mathrm{R}}{ }^{\circledR}$ DNA polymerase (New England Biolabs, Ipswich, MA, USA). DNA amplification was performed on a 2720 Thermal Cycler (Applied Biosystems, Foster City, CA, USA) using a touchdown protocol $\left(94^{\circ} \mathrm{C}\right.$ for $3 \mathrm{~min}, 15$ cycles of $\left[94^{\circ} \mathrm{C}\right.$ for $30 \mathrm{sec}$, starting at $70^{\circ} \mathrm{C}$ decreasing $1^{\circ} \mathrm{C} /$ cycle for $30 \mathrm{sec}, 72^{\circ} \mathrm{C}$ for $1 \mathrm{~min}], 30$ cycles of $\left[94^{\circ} \mathrm{C}\right.$ for $10 \mathrm{sec}, 55^{\circ} \mathrm{C}$ for $45 \mathrm{sec}, 72^{\circ} \mathrm{C}$ for $\left.1 \mathrm{~min}\right], 72^{\circ} \mathrm{C}$ for $7 \mathrm{~min}$ ) to amplify all regions except PCR 4. For PCR 4 (forward primer sequence: GTTTGGAGCCTTCCCTCTCT and reverse primer sequence: AAGCCTGACCACGCTTTCTA), we used a GC-Rich PCR system kit (Roche Molecular Biochemicals, Mannheim, Germany) in a $20 \mu \mathrm{L}$ reaction containing $25 \mathrm{ng}$ of genomic DNA, $0.2 \mathrm{pmol} / \mu \mathrm{L}$ of each 
primer, $0.2 \mathrm{mmol} / \mathrm{L}$ dNTPs, $5 \mathrm{~mol} / \mathrm{L}$ GC-Rich resolution solution, $1 \times$ GC-Rich PCR reaction buffer and $0.04 \mathrm{U} / 50 \mu \mathrm{L}$ GC-Rich Enzyme Mix. The PCR program was as follows: $95^{\circ} \mathrm{C}$ for $3 \mathrm{~min}, 30$ cycles of $\left(95^{\circ} \mathrm{C}\right.$ for $30 \mathrm{sec}, 58^{\circ} \mathrm{C}$ for $30 \mathrm{sec}, 72^{\circ} \mathrm{C}$ for $\left.45 \mathrm{sec}\right), 72^{\circ} \mathrm{C}$ for $7 \mathrm{~min}$. PCR products were separated on a $3 \%$ agarose gel, visualized under UV light after staining with Gel Red (Biotium, Hayward, CA, USA), and purified using ExoSAP-IT enzyme (USB Corporation, Cleveland, OH, USA) to remove unincorporated primers and dNTPs.

A $10 \mu \mathrm{L}$ sequencing reaction was prepared with $90 \mathrm{ng}$ of PCR product, $1 \times$ reaction buffer, $1 \times$ BigDye v3.1 Cycle Sequencing Kit (Applied Biosystems) and $0.32 \mathrm{pmol} / \mu \mathrm{L}$ of primer (forward or reverse). The sequencing reaction was then subjected to thermal cycling $\left(96^{\circ} \mathrm{C}\right.$ for $1 \mathrm{~min}$, followed by 25 cycles of $\left(96^{\circ} \mathrm{C}\right.$ for $10 \mathrm{sec}, 50^{\circ} \mathrm{C}$ for $5 \mathrm{sec}, 60^{\circ} \mathrm{C}$ for $110 \mathrm{sec}$ ), followed by a rapid thermal ramp to $4{ }^{\circ} \mathrm{C}$ ) and run on an automated sequencer (ABI 3730XL, Applied Biosystems) in the DNA Sequencing Service from the Genomics Unit at the Instituto Gulbenkian de Ciência in Portugal. Sequencher 4.10.1 software demo version (Gene Codes Corporation, Ann Arbor, MI, USA) was used to analyze the raw sequence data.

\section{Genotyping}

Five variants were genotyped using a Sequenom iPlex assay (Sequenom, San Diego, CA, USA) according to the manufacturer's protocol, with detection in a Sequenom MassArray K2 platform. The primer sequences (Table S2) were designed using Sequenom MassARRAY Assay Design software version 3.0 and the genotyping assay was performed using the Genotyping Service from the Genomics Unit at the Instituto Gulbenkian de Ciência, Portugal. Extensive quality control was performed with the use of eight HapMap controls of diverse ethnic affiliation, along with sample duplication within and across plates, a Mendelian inheritance check in three large pedigrees, and a call rate for each SNP $>90 \%$. Genotype determinations were performed with the investigators blinded to the affection status (i.e., case or control). Individual DNA samples with genotyping success rate across all SNPs $<85 \%$ were also excluded.

\section{Transcription factor binding sites}

The Integrated Regulation from ENCODE (Transcription Factor ChIP-seq from ENCODE) and the ENCODE Transcription Factor Binding (Transcription Factor ChIP-seq Uniform Peaks from ENCODE/Analysis, ENCODE March 2012 Freeze) tracks on the UCSC genome browser (http://genome.ucsc.edu/) were used to determine if the identified novel variants are located in putative transcription factor binding sites.

\section{RESULTS}

\section{IL10 variant discovery}

To identify novel low-frequency variants in IL10 associated with $\mathrm{BD}$, we first sequenced a $7.7 \mathrm{~kb}$ genomic region encompassing the complete IL10 gene plus $0.9 \mathrm{~kb}$ upstream and $2 \mathrm{~kb}$ downstream of the gene (Chr1: 206.938.978 to Chr1: 206.946.691 in the GRCh37/hg19 assembly), as well as two conserved regions in the putative IL10 promoter $(826 \mathrm{bp}$ at Chr1:206.950.949-206.951.775 and 845 bp at Chr1:206.957.492-206.958.337). This variant discovery was performed by Sanger sequencing of 50 BD Portuguese patients (100 chromosomes), which allows the detection of variants with MAF $>1 \%$. The principal demographic and clinical features of the subjects in the Portuguese dataset are shown in Table 1. The Portuguese cases and controls are age-matched and all patients presented recurrent oral aphthosis. Other common manifestations included genital aphthosis $(89.4 \%)$, skin $(80.2 \%)$, ocular $(45.9 \%)$, joint $(77.3 \%)$, neurological $(20.3 \%)$, vascular $(13.9 \%)$, gastrointestinal (16.2\%) and cardiac (5.5\%) involvement.

In these $50 \mathrm{BD}$ patients, we did not detect rare IL10 coding variants, but we identified 28 known SNPs with MAF ranging from 0.010 to 0.390 , and five previously undescribed single nucleotide variants (SNVs) in a heterozygous state in five $\mathrm{BD}$ patients (Table 2). The novel variants are located in the IL10 $3^{\prime}$ untranslated region (ss836185595), in intron 3 (ss836185596 and ss836185602), and in the putative IL10 promoter region (ss836185598 and ss836185604).

\section{Association of novel SNVs with BD}

To assess if these five novel low-frequency IL10 variants are specific to $\mathrm{BD}$ patients and/or to the Portuguese population, we genotyped them in an additional Portuguese sample (26 cases and 104 controls) and in an Iranian dataset (964 cases and 823 controls) with the demographic and clinical characteristics shown in Table 1. ss836185595 was detected in one Iranian control individual (Table 2) and therefore constitutes a new rare variant found in different populations and not specific to $\mathrm{BD}$ patients. The remaining four SNVs (ss836185596, ss836185602, ss836185598 and ss836185604) were not found in this second Portuguese dataset or in the Iranian cases and controls (Table 2). ENCODE data annotated on the UCSC 
Table 1 Main demographic and clinical features of Behçet's disease (BD) patients and controls in the Portuguese and Iranian datasets

\begin{tabular}{|c|c|c|c|c|}
\hline Characteristic & Portuguese controls & Portuguese BD cases & Iranian controls & Iranian BD cases \\
\hline No. of subjects & 104 & 76 & 823 & 964 \\
\hline Sex, male, no. (\%) & $57(54.8)$ & $18(23.7)$ & 345 (41.9) & $506(52.5)$ \\
\hline Age at examination, mean \pm SD (years) & $36.4 \pm 13.6$ & $36.3 \pm 12.0$ & $40.4 \pm 11.9$ & $39.1 \pm 10.9$ \\
\hline \multicolumn{5}{|l|}{ Clinical symptom, no./total assessed (\%) } \\
\hline Oral aphthosis & 0/104 (0) & $76 / 76(100)$ & $0 / 823(0)$ & $953 / 964$ (98.9) \\
\hline Genital aphthosis & $0 / 104(0)$ & $68 / 76(89.4)$ & $0 / 823(0)$ & $603 / 964(62.6)$ \\
\hline Skin lesions & & $61 / 76(80.2)$ & & $534 / 964(55.4)$ \\
\hline Pseudofolliculitis & & $50 / 76(65.8)$ & & $405 / 964(42.0)$ \\
\hline Erythema nodosum & & $32 / 76(42.1)$ & & 209/964 (21.7) \\
\hline Skin aphthosis & & $7 / 76(9.2)$ & & $30 / 964(3.1)$ \\
\hline Ophthalmologic manifestations & & $34 / 74(45.9)$ & & $577 / 964(59.9)$ \\
\hline Anterior uveitis & & $20 / 74(27.0)$ & & $416 / 964(43.2)$ \\
\hline Posterior uveitis & & $13 / 74(17.6)$ & & $490 / 964(50.8)$ \\
\hline Retinal vasculitis & & $3 / 74(4.1)$ & & $340 / 964(35.3)$ \\
\hline Joint manifestations & & $58 / 75(77.3)$ & & $296 / 964(30.7)$ \\
\hline Arthralgia & & $51 / 75(68.0)$ & & $137 / 964(14.2)$ \\
\hline Arthritis & & $21 / 75(28.0)$ & & 185/964 (19.1) \\
\hline Ankylosing spondylitis & & $1 / 75(1.3)$ & & $18 / 964(1.9)$ \\
\hline Neurologic manifestations & & $15 / 74(20.3)$ & & $61 / 964(6.3)$ \\
\hline Vascular involvement & & $10 / 72(13.9)$ & & $51 / 964(5.3)$ \\
\hline Gastrointestinal manifestations & & $12 / 74(16.2)$ & & $39 / 964(4.0)$ \\
\hline Epididymitis & & $2 / 73(2.7)$ & & $21 / 964(2.2)$ \\
\hline Cardiac involvement & & $4 / 73(5.5)$ & & $6 / 964(0.6)$ \\
\hline Pleuropulmonary involvement & & $2 / 72(2.8)$ & & 6/964 (0.6) \\
\hline Pathergy phenomenon & & $19 / 41(46.3)$ & & $437 / 948(46.1)$ \\
\hline Family history of BD & & $11 / 71(15.5)$ & & $85 / 959(8.9)$ \\
\hline
\end{tabular}

genome browser showed that the reference sequences of these four novel SNVs lie in transcription factor binding sites (ss836185596: Pol2; ss836185602: NFKB, STAT3, TBP, Oct-2, POU2F2, Pol2, and Pol2-4H8; ss836185598: Pol2, NFKB, TCF12, p300, BATF, EBF1_ [C-8], SP1, Oct-2, POU2F2, PAX5-N19, Sin3Ak-20, PAX5-C20, BCLAF1_[M33-P5B11], MEF2A, IRF4_[M17], BCL11A, Egr-1, ZEB1_[SC-25388], YY1; ss8361 85604: NFKB, BCLAF1_[M33-P5B11], MEF2A, BCL11A, Egr-1, YY1 and ELF1_[SC-631]). However, using this tool, we cannot predict if the rare alleles of these variants affect the binding affinities of the transcription factors.

\section{DISCUSSION}

We identified four novel IL10 non-coding variants in four Portuguese BD patients which were absent in Portuguese controls and in a large dataset of Iranian BD cases and controls. Even though the approaches were different (e.g., whole gene sequencing vs. exonic sequencing), our results are consistent with those from a recent report by Kirino et al. ${ }^{7}$ where deep exonic resequencing of IL10 (in 766 patients and 768 matched controls of Japanese or Turkish origin, distributed over 32 DNA pools) led to the identification of five non-synonymous rare mutations (G15R, M40V, R124Q, H127R, K315E). A meta-analysis of the associations (in a dataset of 528 Japanese BD cases and 586 controls and in a dataset of 1933 Turkish BD cases and 1872 controls) showed that these five rare mutations were not collectively associated with $\mathrm{BD}$ in any of the three burden tests assayed. ${ }^{7}$ These authors did not screen the intronic regions of IL10 and therefore it is unclear whether there would be an over-representation of noncoding variants among their patients when compared to controls.

Since the novel low-frequency variants are not in coding regions, we cannot predict their potential functional impact using algorithms such as SIFT ${ }^{12}$ or PolyPhen $2,{ }^{13}$ and therefore we cannot test their association with $\mathrm{BD}$ using currently available tests such as the C-alpha test. ${ }^{14}$ Our work highlights the need to develop bioinformatics and statistical tools capable of estimating the impact of 
Table 2 IL10 variants identified in Behçet's disease (BD) patients

\begin{tabular}{|c|c|c|c|c|c|c|c|}
\hline \multirow[t]{2}{*}{ Variant ID } & \multirow{2}{*}{$\begin{array}{c}\text { Position } \\
\text { (base pairs) } \dagger\end{array}$} & \multirow[t]{2}{*}{ Localization } & \multirow[t]{2}{*}{ Alleles } & \multicolumn{4}{|c|}{ Minor allele frequency } \\
\hline & & & & $\begin{array}{l}\text { Portuguese BD } \\
\text { cases }(n=76)\end{array}$ & $\begin{array}{c}\text { Portuguese } \\
\text { controls }(n=104)\end{array}$ & $\begin{array}{c}\text { Iranian BD } \\
\text { cases }(n=964)\end{array}$ & $\begin{array}{c}\text { Iranian } \\
\text { controls }(n=823)\end{array}$ \\
\hline rs3024505 & 206939904 & Downstream & $\mathrm{A} / \mathrm{G}$ & $0.120(\mathrm{~A}) \ddagger$ & - & - & - \\
\hline rs3024502 & 206940310 & Downstream & $\mathrm{C} / \mathrm{T}$ & $0.360(\mathrm{~T}) \ddagger$ & - & - & - \\
\hline rs3024500 & 206940831 & Downstream & $\mathrm{A} / \mathrm{G}$ & $0.350(\mathrm{G})$ & - & - & - \\
\hline rs3024498 & 206941529 & $3^{\prime}$ UTR & $\mathrm{C} / \mathrm{T}$ & $0.380(\mathrm{C}) \ddagger$ & - & - & - \\
\hline rs3024510 & 206941636 & 3' UTR & $\mathrm{A} / \mathrm{T}$ & $0.010(\mathrm{~A}) \ddagger$ & - & - & - \\
\hline rs3024496 & 206941864 & $3^{\prime}$ UTR & $\mathrm{A} / \mathrm{G}$ & $0.320(\mathrm{G}) \$$ & - & - & - \\
\hline ss836185595 & 206941923 & $3^{\prime}$ UTR & $\mathrm{C} / \mathrm{T}$ & $0.007(\mathrm{~T})$ & $0.000(\mathrm{~T})$ & $0.000(\mathrm{~T})$ & $0.001(\mathrm{~T})$ \\
\hline rs 45587633 & 206942187 & Intron 4 & $\mathrm{C} / \mathrm{T}$ & $0.010(\mathrm{~T}) \ddagger$ & - & - & - \\
\hline rs45611331 & 206942244 & Intron 4 & $\mathrm{C} / \mathrm{T}$ & $0.020(\mathrm{~T}) \ddagger$ & - & - & - \\
\hline rs3024495 & 206942413 & Intron 4 & $\mathrm{C} / \mathrm{T}$ & $0.120(\mathrm{~T}) \ddagger$ & - & - & - \\
\hline rs3024509 & 206943297 & $\begin{array}{l}\text { Intron } 3 \\
\text { (boundary) }\end{array}$ & $\mathrm{A} / \mathrm{G}$ & $0.060(\mathrm{G}) \$$ & - & - & - \\
\hline ss836185596 & 206943312 & $\begin{array}{l}\text { Intron } 3 \\
\text { (boundary) }\end{array}$ & $\mathrm{T} / \mathrm{C}$ & $0.007(\mathrm{C})$ & $0.000(\mathrm{C})$ & $0.000(\mathrm{C})$ & $0.000(\mathrm{C})$ \\
\hline rs3024508 & 206943410 & Intron 3 & $\mathrm{~A} / \mathrm{C}$ & $0.010(\mathrm{C}) \ddagger$ & - & - & - \\
\hline rs1878672 & 206943713 & Intron 3 & $\mathrm{C} / \mathrm{G}$ & $0.370(\mathrm{C}) \$$ & - & - & - \\
\hline rs3024493 & 206943968 & Intron 3 & $\mathrm{~A} / \mathrm{C}$ & 0.140 (A) $\ddagger$ & - & - & - \\
\hline rs3024507 & 206944077 & Intron 3 & $\mathrm{C} / \mathrm{T}$ & $0.020(\mathrm{~T}) \$$ & - & - & - \\
\hline ss836185602 & 206944078 & Intron 3 & $\mathrm{G} / \mathrm{A}$ & $0.013(\mathrm{~A})$ & $0.000(\mathrm{~A})$ & $0.000(\mathrm{~A})$ & $0.000(\mathrm{~A})$ \\
\hline rs3024492 & 206944112 & Intron 3 & $\mathrm{~A} / \mathrm{T}$ & $0.120(\mathrm{~A}) \ddagger$ & - & - & - \\
\hline rs1554286 & 206944233 & $\begin{array}{l}\text { Intron } 3 \\
\text { (boundary) }\end{array}$ & $\mathrm{A} / \mathrm{G}$ & 0.320 (A) $\$$ & - & - & - \\
\hline rs1518111 & 206944645 & $\begin{array}{l}\text { Intron } 2 \\
\text { (boundary) }\end{array}$ & $\mathrm{C} / \mathrm{T}$ & $0.350(\mathrm{~T}) \$$ & - & - & - \\
\hline rs1518110 & 206944861 & Intron 1 & $\mathrm{~A} / \mathrm{C}$ & $0.390(\mathrm{~A}) \ddagger$ & - & - & - \\
\hline rs3021094 & 206944952 & Intron 1 & $\mathrm{G} / \mathrm{T}$ & $0.150(\mathrm{G}) \$$ & - & - & - \\
\hline rs3024491 & 206945046 & Intron 1 & $\mathrm{~A} / \mathrm{C}$ & $0.360(\mathrm{~A}) \ddagger$ & - & - & - \\
\hline rs3024490 & 206945311 & Intron 1 & $\mathrm{~A} / \mathrm{C}$ & $0.370(\mathrm{~A}) \$$ & - & - & - \\
\hline rs2222202 & 206945381 & Intron 1 & $\mathrm{~A} / \mathrm{G}$ & $0.350(\mathrm{G})$ & - & - & - \\
\hline rs5743625 & 206946115 & Promoter & $\mathrm{A} / \mathrm{G}$ & $0.010(\mathrm{~A}) \ddagger$ & - & - & - \\
\hline rs1800872 & 206946407 & Promoter & $\mathrm{G} / \mathrm{T}$ & $0.340(\mathrm{~T}) \$$ & - & - & - \\
\hline rs56299498 & 206946413 & Promoter & $\mathrm{C} / \mathrm{T}$ & $0.010(\mathrm{~T}) \$$ & - & - & - \\
\hline rs1800895 & 206946472 & Promoter & $\mathrm{C} / \mathrm{T}$ & $0.020(\mathrm{~T}) \ddagger$ & - & - & - \\
\hline rs12122923 & 206951397 & Promoter & $\mathrm{C} / \mathrm{T}$ & $0.070(\mathrm{~T}) \ddagger$ & - & - & - \\
\hline rs17015767 & 206951398 & Promoter & $\mathrm{C} / \mathrm{G}$ & $0.150(\mathrm{C}) \$$ & - & - & - \\
\hline ss836185598 & 206957911 & Intergenic & $\mathrm{C} / \mathrm{T}$ & $0.007(\mathrm{~T})$ & $0.000(\mathrm{~T})$ & $0.000(\mathrm{~T})$ & $0.000(\mathrm{~T})$ \\
\hline ss836185604 & 206958076 & Intergenic & $\mathrm{C} / \mathrm{T}$ & $0.013(\mathrm{~T})$ & $0.000(\mathrm{~T})$ & $0.000(\mathrm{~T})$ & $0.000(\mathrm{~T})$ \\
\hline
\end{tabular}

The five variants identified for the first time in this study are highlighted in bold. †The base pair positions refer to the GRCh37/hg19 release. $\ddagger$ Minor allele frequencies in the 50 Portuguese BD patients used in the mutation screen. UTR, untranslated region.

non-coding variants (e.g., in splice sites, in introns or in the promoter region) and to incorporate these predictions into an association test.

The approach to perform mutation discovery in $\mathrm{BD}$ patients only relies on the assumptions that cases carry deleterious mutations and controls do not harbor protective alleles. It is a cost-effective strategy when non-synonymous variations are not found in patients, as it avoids screening the controls. The lack of variant discovery in the controls may introduce a bias in our study as we may have missed protective variants, but this possibility is unlikely and not supported by the study by Kirino et al. ${ }^{7}$

The new variants we identified may play a role in gene expression regulation through modification of transcription factor binding sites or DNA methylation 
patterns, especially those located in the promoter region. At this stage, we lack information on the specific impact of these new variants in IL10 function to decipher whether these polymorphisms contribute or not to $\mathrm{BD}$. Thus, gene expression studies and functional analyses of IL10 variants, as well as the identification of the genetic/environmental factors, are needed to reinforce the potential implication of this gene in the susceptibility to BD.

\section{ACKNOWLEDGMENTS}

We thank Doctor Ahmadreza Niavarani for his valuable help in the genetic laboratory of Rheumatology Research Center. We thank Dr. Majid Zeidi (Iranian Blood Transfusion Organization) for his excellent support. We are thankful to Doctor Alireza Khabbazi (Department of Rheumatology, Tabriz University of Medical Sciences) for his valuable help in selecting control individuals from Turkish ethnicity. We are also deeply grateful to Dr. Vera Teixeira (Hospitais da Universidade de Coimbra), all study participants and to the Genotyping and Sequencing Services from the Genomics Unit at the Instituto Gulbenkian de Ciência.

This work was supported by the Portuguese Fundação para a Ciência e a Tecnologia (grant PTDC/SAU-GMG/ 098937/2008, fellowships SFRH/BD/43895/2008 to JMX, SFRH/BPD/35737/2007 to PA, SFRH/BPD/ $70008 / 2010$ to IS, a Ciência and an Investigator-FCT contract to SAO) and the Research Committee of the Tehran University of Medical Sciences (grant 132/714).

\section{DISCLOSURE STATEMENT}

The authors have declared no conflicts of interest.

\section{REFERENCES}

1 International Team for the Revision of the International Criteria for Behcet's Disease (ITR-ICBD), Davatchi F, Assaad-Khalil S et al. (2014) The International Criteria for Behcet's Disease (ICBD): a collaborative study of 27 countries on the sensitivity and specificity of the new criteria. $J$ Eur Acad Dermatol Venereol 28, 338-47.

2 Remmers EF, Cosan F, Kirino Y et al. (2010) Genome wide association study identifies variants in the MHC class I, IL10, and IL23R-IL12RB2 regions associated with Behçet's disease. Nat Genet 42, 698-702.
3 Mizuki N, Meguro A, Ota M et al. (2010) Genome-wide association studies identify IL23R-IL12RB2 and IL10 as Behçet's disease susceptibility loci. Nat Genet 42, 703-6.

4 Rivas MA, Beaudoin M, Gardet A et al. (2011) Deep resequencing of GWAS loci identifies independent rare variants associated with inflammatory boweldisease. Nat Genet 43, 1066-73.

5 Altshuler D, Daly MJ, Lander ES (2008) Genetic mapping in human disease. Science 322, 881-8.

6 Frazer KA, Murray SS, Schork NJ, Topol EJ (2009) Human genetic variation and its contribution to complex traits. Nat Rev Genet 10, 241-51.

7 Kirino Y, Zhou Q, Ishigatsubo Y et al. (2013) Targeted resequencing implicates the familial Mediterranean fever gene MEFV and the toll-like receptor 4 gene TLR4 in Behçet disease. Proc Natl Acad Sci USA 110, 8134-9.

8 Xavier JM, Shahram F, Davatchi F et al. (2012) Association study of IL10 and IL23R-IL12RB2 in Iranian patients with Behçet's disease. Arthritis Rheum 64, 2761-72.

9 Liang Y, Xu WD, Zhang M et al. (2013) Meta-analysis of association between cytokine gene polymorphisms and Behcet's disease risk. Int J Rheum Dis 16, 616-24.

10 Shah N, Kammermeier J, Elawad M, Glocker EO (2012) Interleukin-10 and interleukin-10-receptor defects in inflammatory bowel disease. Curr Allergy Asthma Rep 12, 373-9.

11 Ben Ahmed M, Houman H, Miled M, Dellagi K, Louzir H (2004) Involvement of chemokines and Th1 cytokines in the pathogenesis of mucocutaneous lesions of Behçet's disease. Arthritis Rheum 50, 2291-5.

12 Ng PC, Henikoff S (2003) SIFT: predicting amino acid changes that affect protein function. Nucleic Acids Res 31, 3812-4.

13 Adzhubei IA, Schmidt S, Peshkin L et al. (2010) A method and server for predicting damaging missense mutations. Nat Methods 7, 248-9.

14 Neale BM, Rivas MA, Voight BF et al. (2011) Testing for an unusual distribution of rare variants. PLoS Genet 7, e1001322.

\section{Supporting Information}

Additional Supporting Information may be found in the online version of this article:

Table S1 Sequences of primers used to amplify IL10 and promoter regions.

Table S2 Sequences of primers used for genotyping the new variants. 